\title{
Faculty Development in Community Colleges: Challenges and Opportunities in Teaching the Teachers
}

\author{
Loretta Howard \\ Canadian Memorial Chiropractic College (CMCC)
}

Nancy Taber

Brock University

\begin{abstract}
This article stems from a qualitative inquiry research project that examined the significant experiences of adult educators. For this article we explore the experiences of our faculty educator participants working within the community college context and examine the ways in which their practice connects to faculty development literature. Key insights gleaned from this research highlight both challenges and opportunities that college faculty developers face today. Our findings call for community college leaders and teachers to more effectively explore the ways in which personal, professional, and institutional epistemologies interact in order to better support learning.
\end{abstract}

Keywords: faculty development, qualitative inquiry, community college.

Loretta Howard, Ed.D. is the Director, Curriculum and Faculty Development at the Canadian Memorial Chiropractic College and a part time faculty member at OISE/UT and Brock University. Her research interests include narrative inquiry, teacher education practices, and workplace learning and change. Email: mlhoward@cmcc.ca.

Nancy Taber, Ph.D. is an Assistant Professor in the Faculty of Education at Brock University. Her research interests include adult education, sociocultural issues in children's literature, and learning war and gender in daily life. Email: ntaber@brocku.ca.

Brock Education, Volume 20, No.1, Fall 2010, 34-48 


\section{Introduction}

This article examines and constructs meaning from the experiences of community college faculty developers. First, we explore recent transitions in Canadian community colleges and examine corresponding changes in the roles and demographics of college faculty members, which has resulted in the establishment of a wide range of faculty development programs. Then, we discuss the methodology of our research exploring the personal experience stories of adult educators. We then focus on the stories of four college educators involved in faculty development and train-thetrainer programs. We detail our thematic findings, organizing them into factors that serve to support or inhibit deep learning at individual and institutional levels: engagement and applied learning; reflective practice; change, growth and transformative practices; resistance; and, organizational constraints. We note that the emergent themes connect strongly to adult learning theories; however, for the purposes of this article, we do not use adult education itself as an analytic lens but examine our themes within a faculty development context. Finally, we discuss the implications of our research, concluding that, at both the individual and organizational levels, those truly interested in meeting the educational challenges of the day will more effectively do so if they explore the ways in which personal, professional, and institutional epistemologies interact in order to better support learning.

\section{Community Colleges: A Transitioning Context}

The Ontario community college system emerged in the 1960s as an alternative to university for learners seeking local community access to a wide range of career-oriented programming including apprenticeship and trades training, student development, and, general education (Skolnik, 2008). Over time, colleges have become dynamic institutions of learning that provide a wide range of academic programs representing virtually every aspect of learning in every field from the arts to science and technology. The credentials colleges confer have also changed, moving from traditional occupational qualifications to certificates, diplomas, and applied baccalaureate degrees (Floyd, Skolnik, \& Walker, 2005).

Along with this academic program and credential evolution, the college system has experienced unprecedented challenges in recent years due to: changing student demographics; societal trends that have increased national and global interdependence; economic trends that have shifted the world to a knowledge-based economy; technological innovation that has radically changed business practices; workplace trends that reflect both an increasing pace and complexity of change with a short half-life of knowledge, as well as employment changes that have increased the need for workers to shift jobs frequently and continually learn and develop new skills; and, fiscal realities that include chronic government under-funding of academic programmes with a complementary increase in requirements for accountability measures and performance expectations (Howard, 2002). Consequently, a stronger demand than ever has been placed on colleges to stay abreast of change in order to better prepare their learners for employment.

The implications of these pressures are far-reaching and affect the ways in which the "community college" is now defined. In response, colleges have reinvented curriculum, including online platforms; provided enhanced access; redefined the roles of learner and educator; responded to the need for increased and ongoing program and professional 
development; demonstrated heightened accountability to constituents; extended their responsiveness to learner and societal needs; and, attempted to shift from an instructional paradigm to one of learning (Tagg, 2008).

\section{College Educator Changes: Credentials and Faculty Development}

What this means for the "traditional" college educator is continual change and relentless demand for innovative teaching and curricular practices to anticipate and meet the needs of the day (Ellyard, 2008). As programs have changed, so too has the need for faculty credentials. Gone are the days when educators were hired primarily based on their vocational expertise. When colleges attained degree granting status, provincial ministry guidelines required that faculty members teaching within those programs have appropriate academic credentials (Ministry of Training, Colleges and Universities, 2000). Furthermore, with many colleges experiencing an era of Baby Boomer retirements, new faculty entering the college system are now generally younger, more credentialed (in degree granting colleges the minimum educational requirement is a Master's degree, with doctorates preferred) and less experienced in teaching at a college level (Watts \& Hammons, 2002). This shift has created an even stronger need for the development of faculty with most institutions creating some form of faculty centre to provide learning support for teachers in areas such as adult learning, curriculum design and assessment, facilitation skills, program development, and educational technology.

Sprouse, Ebbers, and King (2008) describe three categories of faculty development: the development of faculty members encompassing components such as career planning and developing teaching skills; instructional development for the "improvement of course, curricula, and student learning" (p. 988); and organizational development "to maximize organizational effectiveness" (p. 988). Additionally, they outline "elements within the literature... portrayed as having influences on the quality of faculty development: culture of learning, leadership, ownership of goals, and structure and sustainability" (p. 988). This description of faculty development demonstrates its complexity and highlights its link to personal, professional, and organizational levels.

Faculty development has become increasingly recognized as an important element for the success of community colleges (Grant \& Keim, 2002; Sprouse, Ebbers, \& King, 2008; Wallin, 2007), particularly as colleges respond to continuous organizational, economic, political, and social changes (Rouseff-Baker, 2002; Watts \& Hammons, 2002). There have been several successful faculty development programs reported in research (Carusetta \& Cranton, 2009; Murray, 2002; Pittas, 2000; Rouseff-Baker, 2002; Wallin, 2007). It appears that "faculty development, as a formalized, structured, and comprehensive program...has grown in depth, breadth, and scope" (Grant \& Keim, 2002, p. 802) and is increasingly "integrat[ing] professional, personal, curricular, and organizational goals" (p. 802). However, there are still various concerns about the ways in which faculty development is construed and implemented.

For instance, faculty development is often resisted by both faculty members and administrators (Murray, 2002; Watts \& Hammons, 2002), programs are "viewed more as an 'add-on' than a necessity" (Watts \& Hammons, 2002, p. 8) while being perceived as an end on their own instead of a continual means of learning in order to improve the organization (Watts \& Hammons, 2002), and "the faculty development coordinator [often] holds a somewhat powerless position" (Grant \& Keim, 2002, p. 803). Faculty development programs are often not connected to college missions, the success of programs is typically not evaluated, and faculty participation 
"is often minimal" (Murray, 2002, p. 91). Furthermore, faculty development programs are "only infrequently grounded in adult education principles and practices" (Carusetta \& Cranton, 2009, p. 73) despite the importance of adult education in the college teaching context. Connections between theories and practices are seldom made (Carusetta \& Cranton, 2009).

Additionally, many college teachers expect faculty development to focus on the instrumental practicalities of teaching their particular course curriculum. However, as Carusetta and Cranton (2009) argue, faculty development should instead focus on the communicative knowledge of "teaching about teaching" (p. 78). Exploring personal teaching philosophies and pedagogies by "engage[ing] in a great deal of introspection and exploration of who we are as teachers" (p. 78) is not always welcomed (at least initially) by participants. However, it can be a powerful learning experience for participants with enduring implications for their development as educators.

It is clear that faculty development in colleges is a significant, relevant, and multifaceted issue for education today affecting teachers, faculty developers, administrators and, by extension, students. In our research, faculty development quickly came to the fore of our interviews, demonstrating its importance not only in the literature but to our participants as well.

\section{Methodology}

This article stems from a research project that explored the personal experience stories (Denzin in Creswell, 2008) of 29 adult educators. Our research was focused on examining the significant experiences of adult educators and the ways in which their experiences connected to adult education literature and to the field of adult education itself (Taber, Howard, \& Cope Watson, 2010). Due to the importance of the college context in contemporary society (as discussed above), we focus here on our data relating to the practice of our four college participants and their experiences as faculty developers.

Their pseudonyms are Cathy, Lydia, Julie, and Lauren. They have from eight to over 25 years of experience related to teaching adults, whether at the academic, vocational, or corporate levels. They all teach credit courses within certificate, diploma and/or applied degree programs in colleges across Ontario and are involved in consulting work for various public and private organizations providing workplace training programs including train the trainer courses. Cathy holds an M.A.; Lydia, an M.Ed.; and Julie and Lauren hold doctorates in adult education. They additionally teach part time at the graduate level at various Ontario universities. Lydia and Lauren serve as seconded faculty developers within their organizations while Julie coordinates and teaches within a college adult education program. Thus, all are involved in both teaching learners and working to "teach the teachers."

Interviews were open-ended and conducted face-to-face in Ontario by the lead author. Both authors listened to the recordings, conducted separate analyses thematically using open, axial, and selective coding (Neuman, 2006), and then engaged in collaborative analysis sessions. In the collaborative sessions, we discussed the major themes that had arisen from our individual coding processes. Taking each of our final selective codes, we re-engaged with the data in another round of selective coding, arriving at a final total of five themes. We chose to engage in a thematic analysis, focusing on themes as opposed to larger stories, in order to highlight common issues in the participants' educational working lives. In this way, we aim not to generalize their experiences but to search for the ways in which their stories overlap at personal, professional, and institutional levels. 
For this article, we have framed the stories the college teacher participants told in their interviews around the emergent themes related to their faculty development experiences. In our analysis, the themes became grouped as either supporting or inhibiting learning in faculty development programs. Although in the everyday lives of the participants these themes are not quite so clear cut as either supporters or inhibitors, they reflect the ways in which their stories aligned with the best practices and challenges present in their faculty development work.

\section{Findings: Supporting and Inhibiting Engagement in Learning}

When we analyzed our data with a focus on our college system participants and their work in faculty development, we found different stories, yet consistent themes in their interviews. Those supporting learning are engagement and applied learning; reflective practice; and, change, growth and transformative practices. Those inhibiting learning are resistance and organizational constraints. While these themes resonate strongly with adult education literature (i.e., Brookfield, 2006; Cole \& Knowles, 2000; Cranton, 2006; and, Mezirow \& Associates, 2000,), a detailed exploration of adult learning theories is beyond the scope of this paper. Instead, we focus our analysis on the interrelationship between the identified themes and our participants' faculty development context.

\section{Engagement and applied learning}

All participants highlighted the need to involve their learners as integral partners in learning by tailoring content and methods to their needs. In this way, learners engaged in their own learning, thus ensuring it is meaningful to their lives and applicable to their contexts. The role of the educator is to act as a facilitator with particular expertise to assist the learners in their learning journeys by providing choices, opportunities, and support, as well as in helping learners challenge their own understandings. As Cathy explains, educators must not talk at learners, but must work with them to assist them in achieving their goals. "I remember when I first started teaching a colleague said to me "every time you stand in front of your students talking, you are wasting their time' and I have never forgotten that." While a lecture format can be considered an effective method in certain situations, Cathy makes it clear that learners must always have the opportunity to make learning meaningful for themselves.

The centrality of the learner was focused around the importance of making their own informed decisions and being responsible for their own learning. As two participants specifically addressed, learning cannot be forced on learners, but the role of the educator is nonetheless crucial in supporting learning. Lydia stated:

I've come to the conclusion that I can't tell anybody anything but I can certainly ask them a whole bunch of questions that start them thinking differently and so if that's the role that I can play then I end up playing that one a fair bit.

In exploring how she designs learning experiences to engage educators in content that focuses on challenging their own perspectives on learning and education, Julie makes a similar comment. She discusses helping learners see "the light" or a different perspective by exposing them to certain ideas, but allowing them to take control over how they want to incorporate them: 
I find a lot of arts-based strategies have been successful in my practice that allows me to get them there [to a specific result focused on challenging perspectives], through the activities.... There is no way you can make a person get there, you have to help them to see the light, you can't bring the light to them, so to speak. So it's how do I move you to that light so that you can see what you are doing, see who you are, see where you can be, where you want to go, and then you [the learner]...create the strategies to get you there.

Julie has worked to improve her own practice as a faculty developer in order to concomitantly improve the learning and practice of the educators she teaches. Further, the teacher learners engage in their own learning while teacher educators "provide the context and the atmosphere" (Julie). Cathy also highlights the importance of the learner taking responsibility for his or her own learning:

I think that it's a truism that most people forget all the time as teachers and facilitators that the responsibility for the learning lies with the learner... where the responsibility of the learning lies with the facilitator is in creating as many opportunities and choices as he or she possibly can for the learner, fairly and transparently.

For Cathy, teaching educators is a "partnership" where relationships are key to enabling learner engagement. She works to nurture relationships with her learners, working towards understanding in order to create a positive learning experience catered to each unique learner:

If you're going to teach anything ... then the way to do it is to present or expose the person to the possibilities, to understand that the person may not learn the way you do, may not share your value system, may not even understand your culture, and so to provide... the learner with the widest possible of choices within a framework that both you and the learner have agreed on.

The modeling of adult learning principles in practice was mentioned by all participants as important to their professional practice and crucial to enabling participants to successfully engage learners. The need to start where the learner is and establish a framework in which learners can engage highlights the importance for educators to understand their learners' needs and contexts and to understand the learning process itself: "I don't understand how you can be a good facilitator if you don't understand the theory of how people learn" (Cathy).

However, the participants recognized the centrality of their own roles in not only providing learning support, but in challenging learners to take risks, incorporate new perspectives, and broaden their own horizons. This idea of encouraging change and growth is integrated in their educational approaches and practices.

\section{Change, growth, and transformative practices}

All participants discussed working with their learners through a transformative process of learning. Many of them indicated that being able to successfully facilitate a process of change and growth with their learners was central to their motivation and satisfaction as teacher educators. As Lydia noted, her learners are "going through transformation and I get to watch all 
that and influence that - I can see all the stages of the transformation and know that I have been a part of the process - how cool is that?"

In speaking further of her learners Lydia describes her ultimate success with a challenging faculty group: "it was a frustrating process, but then all of a sudden something happened - and oh my god, they changed. Transformation!" She relayed one particular success story:

I remember [one teacher] who sat there resisting and resisting and yet at the end of the day, he was a teacher who needed and wanted help to engage his learners more with applied activities and when he finally engaged - he was amazing. And I played a part in changing that perspective - to help him to learn how to do things differently. ...

As Lauren adds:

Faculty often see faculty development as an add-on to the "real" work they do. They are told their credentials are important and are hired for ... knowledge expertise - so they try to be efficient about any faculty development work they do because they have limited time and, as an "add-on", it is not a priority. Sharing their content expertise in the classroom is their priority. ... Some faculty simply don't get that they need to learn how to translate their wonderful content expertise into strong curriculum design and facilitation strategies until they start to get feedback from their learners... Then they recognize that they need to change, but it is upsetting to them because they can take it personally. They have to be able to see that it isn't their subject matter expertise that is in question it is their facilitation of it that is often the problem. Once they see that their expertise is simply the "what" and that adult learning theory in practice is the "how" they are more open to learning how to connect the two together and achieve positive learning for both their learners and themselves... and off they go on an incredible learning journey that completely transforms them.

One participant spoke of the empowering nature of working through transformative processes and the need to explore it more: "It is a very empowering process of self discovery and awareness that we don't learn as much about as we could or should" (Julie). At the root of the transformative learning process is the ability to critically reflect. In order to facilitate that process effectively the teacher educator herself must be able to engage in high levels of reflection as well.

\section{Reflective practice}

All participants noted the importance of critical reflection for their learners and demonstrated their own highly self reflective practice as educators. Cathy spoke of the intimacy of this process of going inward on self:

I struggled with reflection because it's not fun, it has to be still and silent and that is hard for me. It is not a public process; it is an intimate process - you are coming into yourself, layer by layer, and this process is totally critical to effective development as an educator. 
Others indicated that the reflective process created space for the integration of theory in practice:

At some point it was suggested to me ... that there was a place in teaching practice for theory and reflection and I did what most teachers did, I resisted, and then I gradually bought into it, and then I started to see the relevance of it and then I read things on my own and found myself reflecting on how the theories of adult learning integrated with my practice. I found that reflection allowed me to complement my experiential orientation with an increased understanding of theory. The end result of which is a stronger overall skill set. This is what I hope my learners achieve as well. (Lydia)

Another participant spoke to the connection between resistance and reflective practice wherein the process of engagement with critical reflection becomes a means to overcoming resistance. As Julie indicated:

Teachers need to see themselves and their practice under a spotlight, so the reflective practitioner notion, they need to get immersed in that. Once they can see themselves in a variety of ways around who they are, what their practice is, what they are doing, where it came from, how it contributes to who they are as a teacher now, how they got there with it - if you could get a true composite of that - then they would be able to look at it - and it would help them open up and break down barriers and see themselves in a new light. 'Ok, this is what I am, this is what I want to become, now, how do I get there?' And if we could figure out ways of helping them see who they are now and what they want to become then we could help provide a bridge to help them see learning as a process rather than a one shot deal.

The link between reflection and transformation is noted by Julie:

You are dealing with adults who already ... come with set ideas and ways, an educational background, life experience, cultural norms, values, and theories that they've created for themselves that are the bedrock of who they are and now I am trying to influence and change that. ... that is where the difficulty lies. It is being able to shake that without breaking it up that is the secret of dealing with adult learners and knowing how to do that successfully takes a lot of research, education and reflective inquiry on the part of the educator. It is not just looking at the research but understanding what you can do with it in your practice that makes it come alive for your learners and helps them in their process. Reflection is the key.

While the goal for all teacher educators is to promote engagement with learning, growth, transformation and reflective practice, there are barriers that often impede the process. Two areas of concern raised by our participants are resistance to learning and organizational constraints.

\section{Resistance}

Participants noted that, in general, faculty members are notoriously resistant to learning about teaching: 
I quickly discovered that teachers resisted learning about these issues, which was interesting and disturbing to me. I found out that [adult learning] is not something they wanted to touch even though it is an area that they needed to learn more about (Julie).

The participants noted that teachers in their classes were often only interested in the "quick fix" that would solve an immediate crisis or issue. Rather than seeing faculty development as an opportunity to engage in a process of learning and to learn how to better facilitate that same process in their own classes, they were only interested in the product:

Most of my teachers wanted to have that one shot in the arm. They didn't have the ability to see learning as a process but only as a product - which right there shows what they understand about learning in general and, in particular, demonstrates their need for the very development that they resist (Julie).

A number of the participants believed that part of the reason for teacher resistance was because faculty members, who increasingly come to colleges with higher levels of credentials, often hold the view that the credential itself, and its underlying subject matter expertise, will somehow translate into effective teaching skills. Lydia describe a particular teacher "whose attitude was 'I' $\mathrm{m}$ a $\mathrm{PhD}$... and I don't need you'" and the difficulty she had helping him understand that his subject matter expertise was only one part of the teaching and learning equation. In order for teachers to embrace learning about teaching they "have to admit that they have deficiencies in that area - and that is hard for teachers to recognize and admit. They are SMEs [Subject Matter Experts] and think that this automatically translates into good practice, but it doesn't" (Julie). Further, she noted that often teachers' espoused theory and theory in use were not congruent with each other: "I think the espoused theory is not in congruence with the enacted because the teachers have not gathered enough knowledge about self and practice to recognize that espoused theory is not true practice - it is just talk."

One aspect of this barrier to learning is discussed by Julie:

I find resistance is often driven by fear - of sensing that they are not as aware as they should be or as competent as they think they should be - afraid to get "caught with their constructs down" - as in Kelly constructs [George Kelly, Personal Construct Theory] . What I constantly wonder is: what is the difference between somebody who finally gets it and one who doesn't? You lead 10 horses to water - they are all thirsty - but only 6 drink - what is it that makes them drink or not? Is it the timing? Right place, wrong time? Not the right context? But for some folks it is never the right time, place, context ... There are some you can try as hard as you might, but nothing is going to happen.

While many participants noted resistance expressed as an individual construct, resistance was also noted at the institutional level.

\section{Organizational constraints}

Participants identified many institutional difficulties that inhibited learning. For one participant, there was a large disconnect between what the college presented as their value for ideal teaching 
practices and how the policies in place actually constrained, instead of enabled, good teaching. As Lauren asked, "If we know so much about adult learning theory, why aren't we doing it more?"

Lauren's story is emblematic of common challenges faced by faculty developers. In her institution, new faculty members are required to take a faculty development program to assist them in learning about their teaching role. She discussed that there were continuous changes to the program that watered down the content, reduced contact hours, condensed the training schedule, and increased the stress of both the faculty developers and their teacher learners. Frequent changes to the institutional hierarchy, little buy-in from administrators, and unionmanagement disputes over workload issues related to faculty development further exacerbated the challenges that the faculty developers experienced.

In the past three years our program has become a shadow of its original intent and potential. Due to any number of constraints organizationally ... our faculty are coming into the program already stressed and out of the program knowing less and less, are frustrated with the organization and are incredibly overwhelmed. Everything a college could possibly do wrong to them, while espousing to be a learning-centred environment, and trying to practice true... adult learning principles, and telling them how important it is that they do this in their own classroom, is completely lost to them. (Lauren)

Cathy also mentioned the challenges of working in a community college, feeling that "you have to be a... special kind of person to thrive in a community college environment because there aren't a lot of rewards and most of them are intrinsic rewards that... you have to discover on your own." For her, the intrinsic reward of making a difference in a learner's life outweighs the ways in which she feels her work is not appropriately valued by her institution. The importance of having organizational systems aligned to support learning for faculty members was stressed by many of the participants. For some, individual resistance was viewed as a consequence of organizational constraints and systems that were not working as they should to promote an environment in which the exploration of educational philosophies and learning to teach are authentically encouraged and valued:

When some of your learners are new faculty who have no idea what courses they are teaching in a few short weeks, who have no office, no telephone, no real orientation to the college, their department or program, no resources to begin planning the courses that they don't yet know they are teaching... it is little wonder that they come to this training already overwhelmed and stressed. Their basic needs have not been adequately met by the organization and we then walk into class and have an expectation that they will be able to engage effectively and be critically reflective practitioners. No wonder we all hit a wall. We need to support our faculty properly so they can come to class able to learn. (Lauren)

For Lauren, the institution precipitated negative change and hampered positive change while, for Cathy, the institution was made irrelevant to her own practice. In order to work in a positive way and improve her own experiences as well as those of her learners, Cathy ignored the institutional constraints and focused on her individual work in her own classroom. 


\section{Implications}

In our analysis, the central construct of engagement with learning emerged as the primary interpretive lens, allowing us to then scaffold the remaining themes into place as those that contributed either to promote or inhibit engagement. In this view, those aspects that promoted engagement also supported applied learning, fostered growth and constructive change, led or contributed to transformation, relied on reflective knowledge and practice as an integral part of continual learning, valued practice that is dedicated to learners and their needs, and encouraged a teacher identity and philosophy of practice that expanded from one based on content expertise alone. Conversely, those that inhibited engagement with learning created barriers to learning, change, and growth, which included organizational constraints, systemic and or structural issues, and created resistance to learning.

We further noted that this lens of engagement with learning with its opposing aspects of promoters and inhibitors could also be applied at both the individual and organizational levels. From an individual perspective, where learners were able to make connections between the theories of learning and their practices, greater engagement in learning occurred, resulting in transformative insights and thus deeper learning for many, similar to what Carusetta and Cranton (2009) found in their discussion of a community college exemplar. In our research, the faculty developers demonstrated strong insight into the needs of their faculty learners, were highly engaged in critical reflection about how to help their learners through a transformative process, were focused less on the "what" (content) and more on the "how" (facilitation of learning), and were able to design and lead a process to bring their learners, in the words of Julie, "into the light."

Conversely, when the learners were too overwhelmed due to workload or other individual or organizational constraints, resistance to learning was strongly exhibited as an inhibitor that was difficult to overcome; consequently, mere surface learning, if any at all, resulted. In these cases faculty developers clearly reflected the "powerlessness" of their positions (Grant \& Keim, 2002) to influence change at administrative and organizational levels.

The participants in this study explored their own personal educational philosophies in order to improve their practice as faculty developers; this exploration was congruent with the intended learning of their faculty development programs and appears to be consciously modeled by the participants with their learners. It seems however that faculty developers are more able to "give space" to an exploration of a philosophy of practice in an environment where promoters of engagement in learning exist. Where organizational constraints or resistance exists, it is more challenging for faculty developers (and, consequently, their learners) to explore educational philosophies.

From the organizational context, a promoter of engagement was demonstrated in that all of the colleges in which these teacher educators work have formal faculty development programs and processes. Faculty development in these colleges has become "institutionalized" (Watts \& Hammons, 2002, p. 8) and embraced on some level. Conversely, even though the organizations have valued these programs by committing resources to them, there is an apparent disconnect between espoused values and enacted practice, when administrators and faculty members resist participating in and/or supporting faculty development programs (Murray, 2002). College leaders, rightly so, want faculty who are able to promote learning effectively in the classroom but, as in the story of Lauren, often focus too narrowly on the end product rather than understanding that supports need to be in place institutionally to provide the means (the process 
of faculty development) to the end (the product of a "good" teacher). This emphasis on the end rather than the means of faculty development is a parallel view to those faculty members who wanted the "quick shot in the arm" solution to making their practice better rather than understanding that their learning is a process itself.

As Watts and Hammons (2002) note: "when professional development is seen more as a means, the focus shifts beyond the program to the organizational level. .....and it can more appropriately focus on the linkage between programmatic activities and the accomplishment of organizational goals" (p. 8). Organizational support for learning, in addition to the development, delivery, and assessment of faculty development programs themselves, is required in order to enable learner engagement for faculty developers, faculty learners, and students.

\section{Conclusion}

Three key insights gleaned from this research underpin both the challenges and opportunities that college teacher educators face today. Each would benefit from further research and understanding. First, given the demands on and challenges faced by community colleges today, now more than ever, it is important that educators have the necessary abilities and understandings to teach for success in a time of persistent change. Hiring new faculty for their academic credentials is not enough; a strong understanding of learning principles, the development of a broader teaching philosophy that includes both subject matter expertise and an appreciation for and engagement with the scholarship of teaching and learning, through faculty development, is required to assist teachers to make the transformative shift in identity from being subject matter experts (SME) to being educators of subject matter (ESM).

Second, college teacher educators clearly play a crucial role in faculty development. It is interesting to note the congruency between current research on faculty development (Grant \& Keim, 2002; Rouseff-Baker, 2002; Watts \& Hammons, 2002; Sprouse, Ebbers, \& King, 2008; Carusetta \& Cranton, 2009) and the experiences of our participants. The participants in this study demonstrated engagement in exploring their philosophy in practice and clearly based this on an examination of learning pedagogies. Those teacher learners that came "to the light" demonstrated the start of their own transformational process of philosophical and practical explorations. When unrestrained by institutional constraints, their authentic expertise in facilitating learners through a process of growth and development is critical to teacher support and success and, as a result, the attainment of organizational priorities such as student achievement. This cries for a re-examination of the power constructs at play within faculty development and calls for a renewed vision and value of developers' roles.

Third, it is clear that, at both individual and organizational levels, knowledge of how to effectively link learning principles in practice is critical to the success of faculty development programs and the participants within them. Our participants highlight the need for a thorough understanding of learning theory at all levels of the organization and for organizational systems to be aligned to support it. Where this exists, deeper learning occurs with faculty; where it does not, surface, if any, learning occurs.

There is a strong need to more effectively align professional and institutional epistemologies with enacted practices that are congruent with learning pedagogies and principles that focus on learners. As such, college leaders are encouraged to evaluate their faculty development programs and the systems and processes that enable or inhibit them, with an eye to the degree to which effective learning pedagogies are put into practice, not just in the faculty educator's classroom, but also in the organization itself to support teachers to learn, and as a 
consequence to enable continuous engagement in learning for faculty members and their students. 


\section{References}

Brookfield, S. (2006). The skillful teacher: On technique, trust, and responsiveness in the classroom (2nd ed.). San Francisco: Jossey Bass.

Carusetta, E. \& Cranton, P. (2009). Learning to teach: An illustrative case from the Canadian Community College System. New Directions for Adult and Continuing Education, 124, 73 81.

Cole, A. L., \& Knowles, J. G. (2000). Researching teaching: Exploring teacher development through reflexive inquiry. Boston: Allyn \& Bacon.

Cranton, P. (2006). Understanding and promoting transformative learning: A guide for educators of adults. ( $2^{\text {nd }}$ ed.). San Francisco: Jossey Bass.

Creswell, J. W. (2008). Educational research: Planning, conducting, and evaluating quantitative and qualitative research (3rd ed.). Upper Saddle River, NJ: Pearson Education.

Ellyard, P. (2008). Designing 2050: Pathways to sustainable prosperity on Spaceship Earth. Melbourne, AU: TPNTXT.

Floyd, D., Skolnik, M., \& Walker. K. (2005). The community college baccalaureate: Emerging trends and policy issues. Stirling, VA: Stylus Publishing.

Grant, M.R. \& Keim, M.C. (2002). Faculty development in publicly supported two-year colleges. Community College Journal of Research and Practice, 26, 793-807.

Howard, L. (2002). The lived experience of college faculty: Workplace change, workplace learning? Unpublished doctoral thesis. Ontario Institute for Studies in Education/University of Toronto.

Kelly, G.A. The psychology of personal constructs. New York: Norton, 1955.

Mezirow, J. \& Associates. (2000). Learning as transformation: Critical perspectives on a theory in progress. San Francisco: Jossey Bass.

Ministry of Training, Colleges and Universities. (2000). Directives and guidelines for applying for Ministerial consent under the Post-secondary Education Choice and Excellence Act, 2000.

Murray, J.P. (2002). The current state of faculty development in two-year colleges. New Directions for Community Colleges, 118, 89-97.

Neuman, W. L. (2006). Social research methods: Qualitative and quantitative approaches (6th ed.). Boston: Pearson Education.

Pittas, P.A. (2000). A model program from the perspective of faculty development. Innovative 
Higher Education, 25(2), 97- 110.

Rouseff-Baker, F. (2002). Leading change through faculty development. New Directions for Community Colleges, 120, 35-42.

Skolnik, M.L. (2008). Community Colleges in Canada. In P.A. Elsner, G.R. Boggs, and J.T. Irwin (Eds.), Global Development of Community Colleges, Technical Colleges, and Further Education Programs (41-50). Washington, DC: Community College Press.

Sprouse, M., Ebbers, L.H., \& King, A.R. (2008). Hiring and developing quality community college faculty. Community College Journal of Research and Practice, 32, 985-998.

Taber, N., Howard, L. \& Cope Watson, G. (2010). Researcher subjectivities as a conceptual frame in collaborative research: How exploring the experiences of adult educators led to examining researcher lenses. Canadian Journal for the Study of Adult Education, 23(1), $39-54$.

Tagg, J. (2008). Changing minds in higher education: Students change, so why can't colleges? Planning for Higher Education, 37(1), 15-22.

Wallin, D. L. (2007). Part-time faculty and professional development: Notes from the field. New Directions for Community Colleges, 140, 67-73.

Watts, G.E. \& Hammons, J.O. (2002). Professional development: Setting the context. New Directions for Community Colleges, 120, 5- 10. 